\title{
Advances in physical activity monitoring and lifestyle interventions in obesity: a review.
}

Citation for published version (APA):

Bonomi, A. G., \& Westerterp, K. R. (2012). Advances in physical activity monitoring and lifestyle interventions in obesity: a review. International Journal of Obesity, 36(2), 167-177. https://doi.org/10.1038/ijo.2011.99

Document status and date:

Published: 01/02/2012

DOI:

10.1038/ijo.2011.99

Document Version:

Publisher's PDF, also known as Version of record

Document license:

Taverne

Please check the document version of this publication:

- A submitted manuscript is the version of the article upon submission and before peer-review. There can be important differences between the submitted version and the official published version of record.

People interested in the research are advised to contact the author for the final version of the publication, or visit the DOI to the publisher's website.

- The final author version and the galley proof are versions of the publication after peer review.

- The final published version features the final layout of the paper including the volume, issue and page numbers.

Link to publication

\footnotetext{
General rights rights.

- You may freely distribute the URL identifying the publication in the public portal. please follow below link for the End User Agreement:

www.umlib.nl/taverne-license

Take down policy

If you believe that this document breaches copyright please contact us at:

repository@maastrichtuniversity.nl

providing details and we will investigate your claim.
}

Copyright and moral rights for the publications made accessible in the public portal are retained by the authors and/or other copyright owners and it is a condition of accessing publications that users recognise and abide by the legal requirements associated with these

- Users may download and print one copy of any publication from the public portal for the purpose of private study or research.

- You may not further distribute the material or use it for any profit-making activity or commercial gain

If the publication is distributed under the terms of Article $25 \mathrm{fa}$ of the Dutch Copyright Act, indicated by the "Taverne" license above, 


\title{
Advances in physical activity monitoring and lifestyle interventions in obesity: a review
}

\author{
AG Bonomi ${ }^{1,2}$ and KR Westerterp ${ }^{1}$ \\ ${ }^{1}$ Department of Human Biology, Maastricht University, Maastricht, The Netherlands and ${ }^{2}$ Medical Signal Processing, Philips \\ Research Laboratories, Eindhoven, The Netherlands
}

Obesity represents a strong risk factor for developing chronic diseases. Strategies for disease prevention often promote lifestyle changes encouraging participation in physical activity. However, determining what amount of physical activity is necessary for achieving specific health benefits has been hampered by the lack of accurate instruments for monitoring physical activity and the related physiological outcomes. This review aims at presenting recent advances in activity-monitoring technology and their application to support interventions for health promotion. Activity monitors have evolved from step counters and measuring devices of physical activity duration and intensity to more advanced systems providing quantitative and qualitative information on the individuals' activity behavior. Correspondingly, methods to predict activity-related energy expenditure using bodily acceleration and subjects characteristics have advanced from linear regression to innovative algorithms capable of determining physical activity types and the related metabolic costs. These novel techniques can monitor modes of sedentary behavior as well as the engagement in specific activity types that helps to evaluate the effectiveness of lifestyle interventions. In conclusion, advances in activity monitoring have the potential to support the design of response-dependent physical activity recommendations that are needed to generate effective and personalized lifestyle interventions for health promotion.

International Journal of Obesity (2012) 36, 167-177; doi:10.1038/ijo.2011.99; published online 17 May 2011

Keywords: accelerometer; physical activity recognition; doubly-labeled water; energy expenditure

\section{Introduction}

The prevalence of obesity in the US is $32 \%$ among adult men and $37 \%$ among adult women, and even if this prevalence in the US seems unlikely to increase at the same rate as over the past 10 years, it is rising in countries throughout the world, reaching $20-30 \%$ in some European countries and $70 \%$ in Polynesia. ${ }^{1}$ Obesity represents a strong risk factor for developing diseases, such as diabetes, cardiovascular diseases, hypertension and cancer; this is one of the reasons why obesity is considered one of the most serious public health challenges. ${ }^{2}$ Strategies for disease prevention and health promotion often include guidelines on lifestyle changes that encourage participation in physical activity. ${ }^{3}$

Physical activity can be defined as any voluntary body movement generated by the contraction of skeletal muscles resulting in energy expenditure. ${ }^{4}$ As early as in the

Correspondence: Dr AG Bonomi, Department of Human Biology, Maastricht University, Universiteitsingel 50, P.O. Box 616, 6200 MD Maastricht, The Netherlands.

E-mail: a.bonomi@maastrichtuniversity.nl

Received 10 September 2010; revised 17 February 2011; accepted 4 April 2011; published online 17 May 2011
Hellenistic period, about five centuries before Christ, when epidemiological research and statistical methods did not exist, the Greek physician and philosopher Hippocrates recognized the link between regular physical activity and health. ${ }^{5}$ He stated that the right amount of physical activity and exercise is the 'safest way to health'. Nowadays, the crucial role of a physically active lifestyle for maintaining and improving physical, physiological, and psychological health is recognized internationally. ${ }^{3}$ Regular participation in physical activity is associated with numerous health benefits essential for reducing the risk of chronic diseases and adverse health conditions, such as type 2 diabetes, ${ }^{6}$ cardiovascular diseases, ${ }^{7,8}$ osteoporosis, ${ }^{9}$ and breast and colon cancer. ${ }^{10}$ Furthermore, physical activity results in energy expenditure, which plays a fundamental role in the regulation of body weight and the development of obesity. ${ }^{11}$

Increasing physical activity in obese individuals is problematic because of the high metabolic costs that have to be sustained. Indeed, obese individuals are normally less physically active ${ }^{12}$ and spend more time sitting than age-matched lean controls, ${ }^{13,14}$ but the energy expenditure for physical activity on a daily basis is not significantly different. ${ }^{15-17}$ The reason is that the metabolic costs of many activities, such as weight-bearing activities like walking ${ }^{18}$ 
Activity monitoring and health

AG Bonomi and KR Westerterp

and light-intensity activities, ${ }^{19}$ are proportional to body weight. Thus, obese subjects utilize significantly more energy than lean ones in performing the same physical task. This indicates that increasing physical activity in obese subjects is challenging because of the higher activity intensity and high rates of energy expended due to the excess body weight. In this context, objective and accurate measurements of physical activity and of the related physiological responses are urgently needed to make it possible to design successful and tailored intervention strategies for increasing physical activity and to establish what dose of physical activity is necessary for obtaining a specific health benefit. $^{20-22}$ Although the concept of 'the more the better' has been embraced by current public health guidelines on physical activity, many individuals not likely to participate in physical activity might gain health benefits simply by following more effective and personalized activity recommendations. This would certainly help us to beat the global challenge of reversing the epidemic spread of adverse health conditions.

Reviewed here are the recent methodological advances of physical activity monitors for quantifying physical activity and predicting energy expenditure in relation to their use in clinical practice to support lifestyle interventions for health promotion. This review is organized in the following parts: first, a brief introduction of the available methods to measure physical activity is given; second, pedometers and accelerometers, measuring systems of physical activity, are described. The characteristics of the first generation of accelerometers are presented as well as the latest developments in acceleration sensors' technology. Third, accelerometer-based physical activity recognition is introduced as innovative data analysis approach to improve measurements of physical activity. Subsequently, the estimation of energy expenditure with accelerometers is reviewed by describing the latest attempts for reducing estimation errors. In conclusion, advances in accelerometer sensors and data analysis are presented as tools to support the design of physical activity recommendations optimized to the desired health outcome.

\section{How to measure physical activity}

Physical activity is a multi-dimensional behavior characterized by several aspects, such as duration, intensity, frequency and type. A variety of methodologies has been developed to measure physical activity in the field and to analyze the relationship between physical activity and health outcomes. $^{20}$ These can be divided into subjective and objective methods. The subjective methods include direct observations, diaries, activity logs, recall and questionnaires. These are very popular methods for quantifying physical activity in large-scale studies because of their relatively low cost and ability to contextualize the purpose of physical activity. ${ }^{20,23}$
However, subjective methods often provide a biased assessment of physical activity and cannot explore the diverse quantitative aspects of physical activity. Objective methods measure physiological outcomes, like metabolic cost, heart rate and body temperature, ${ }^{20,24}$ or biomechanical effects, like acceleration and displacement, associated with physical activity. ${ }^{20,24-26}$ They generally provide a reliable assessment of physical activity; ${ }^{27}$ however, because of the need for expensive tools, they have limited applicability in large studies.

Ideally, physical activity should be measured with objective techniques in free-living conditions, for a period of time representative of the habitual activity level, with minimal discomfort for the user, and with inexpensive systems. Pedometers and accelerometers reasonably satisfy these requirements, and therefore have been widely used in field research and clinical trials for the assessment of physical activity. $^{23,25,26}$

\section{Pedometers}

Pedometers are activity monitors capable of quantifying physical activity by detecting and counting the steps taken during ambulatory activities. These measuring tools of physical activity are highly unobtrusive, relatively inexpensive and can operate for long periods, but the major advantage is the fact that users can easily interpret pedometer output to receive feedback on their own physical activity. These are some of the reasons why pedometers have been endorsed by national programs to improve physical activity for health promotion. Indeed, pedometers significantly increase the motivation of individuals to achieve targets during lifestyle interventions and as such they can help them reach a higher activity level. ${ }^{28,29}$ Previous studies showed the positive effect of pedometer use on key health outcomes. ${ }^{28}$ Furthermore, monitoring ambulatory activities is important because walking is a popular leisure-time activity that is difficult to recall using subjective methods like questionnaires or diaries. ${ }^{30}$

Today, dozens of pedometers are commercially available and the vast majority are equipped with a mechanical switch (spring-levered pendulum) or an inertial sensor to measure the amplitude of body movement and detect steps by using proprietary systems ranging from hardware counters to software algorithms for signal processing and step detection. ${ }^{31}$ Many studies have been conducted to test the accuracy of pedometers for measuring steps and predicting activity energy expenditure. Under laboratory conditions the step count error (50-90\%) of spring-levered pedometers was high at slow walking speeds (below $4.5 \mathrm{~km} \mathrm{~h}^{-1}$ ). Furthermore, greater body mass index, waist circumference and tilt angle were shown to reduce the step count accuracy of spring-levered pedometers. ${ }^{31,32}$ Thus, concerns have been raised about the use of this type of pedometer in obese 
subjects, who also have a tendency to ambulate at slower speeds. $^{31,33}$

Inertial and spring-levered pedometers have distinctive characteristics that produce a different degree of accuracy. A study by Crouter et al. ${ }^{31}$ showed that an inertial pedometer based on a piezoelectric sensor, a system capable of measuring the variation of the applied acceleration forces during movement, was insensitive to subject characteristics and tilt angle. However, the step count error (7\%) was still significant at slow walking speed $\left(3.2 \mathrm{~km} \mathrm{~h}^{-1}\right)$. Indicatively, inertial pedometers should be preferred to spring-levered ones for measuring physical activity in overweight and obese subjects; however, their cost can be 10 times higher.

Intrinsic disadvantages of using pedometers to measure physical activity are the insensitivity to non-ambulatory activities and the fact that most of the available pedometers do not provide accurate information on the metabolic cost of physical activity. Only a few studies have shown an association between pedometer output and activity energy expenditure. Laboratory trials showed that step count was associated with walking energy expenditure as measured using indirect calorimetry $\left(R^{2}\right.$ around $\left.60 \%\right) .{ }^{34}$ On the other hand, free-living trials showed a general disagreement between pedometer output and doubly-labeled water measures of energy expenditure in both normal and overweight subjects. ${ }^{26,34,35}$ However, in elderly and certain patient populations in which walking represents the major type of activity engaged in, a pedometer step count could explain $36-37 \%$ of the variability in free-living activity energy expenditure. This means that estimates of energy expenditure based on step count are imprecise on the group and individual levels, especially as the additive role of body weight and subjects' characteristics in explaining the variation in ambulatory metabolic requirements has not yet been clarified.

Although pedometers are affordable tools for motivating people to be more active, their poor accuracy in detecting steps at slow speed and their unreliable estimation of energy expenditure could generate counterproductive effects and result in frustration and low compliance with an intervention program. ${ }^{33,36}$ In recent years, step-counting applications have been developed for advanced mobile phones with embedded inertial sensors and global positioning systems. ${ }^{37}$ These instruments, although still expensive, might offer interesting scenarios for future campaigns for health promotion as pedometer software applications may reach a high degree of accuracy given the rich sensorial and contextual resources available through mobile phones, whose market penetration is rapidly growing. ${ }^{38}$

\section{Accelerometers}

Accelerometry-based activity monitors, often called accelerometers, are portable sensor systems able to quantify physical activity by measuring the acceleration of the human body during movement. Accurate and unobtrusive measurements of physical activity are achieved only when the accelerometer has certain physical and technical characteristics in terms of dimensions, weight, and amount of information processed and recorded.

Unlike pedometers, accelerometers are sensitive to any activity type engaged in during the day. Consequently, accurate measurements of physical activity can be achieved when the acceleration is collected at a frequency sufficient to ensure that any human motion is captured. The variability of the acceleration of the body during physical activity differs according to the measurement location. At the waist level, $95 \%$ of the variability can be determined by frequencies within $10 \mathrm{~Hz}^{25,39}$ and the amplitude does not exceed $6 \mathrm{G}$ in magnitude $\left(1 \mathrm{G}=9.8 \mathrm{~m} \mathrm{~s}^{-2}\right){ }^{25}$ This indicates that an accelerometer should record the body acceleration at a proper frequency, and it should be able to process the information to reduce noise and retain characteristics of the acceleration pattern so as to describe properly physical activity intensity, duration and type. This requires complex and frequent operations computed by the activity monitor, which shortens battery life.

Unobtrusive monitoring is achieved when the accelerometer does not interfere with the subject's normal behavior. Small dimensions, lightweight, single-site placement and long operational lifetime are crucially important for unobtrusive monitoring. However, small, lightweight devices usually have a short battery life because the amount of energy that the battery can provide is directly proportional to its volume and weight. ${ }^{40}$ The operational lifetime can be defined as the minimum between the battery life and the time to fill up the device's memory. Ideally, unobtrusive accelerometers should support an operational lifetime of a few weeks or months, to improve users' familiarity with the measuring system and reduce interference with the normal behavior.

\section{Piezoelectric accelerometers}

The first generation of accelerometers consisted of piezoelectric acceleration sensors, with dimensions ranging from 7 to $120 \mathrm{~cm}^{3}$, weight $17-50 \mathrm{~g}$ and the ability to measure physical activity continuously for 9-45 days, depending on the accelerometer. ${ }^{41}$ Examples of the most commonly used activity monitors are the Actigraph (Actigraph, Pensacola, FL, USA), the RT3 (StayHealthy, Monrovia, CA, USA), the Actical (Philips Respironics, Chichester, UK), and the Tracmor (Philips Research, Eindhoven, The Netherlands). These accelerometers were relatively small and lightweight, and their long operational lifetime was often accomplished by limiting the amount of information on body movement collected. Physical activity was assessed by determining activity counts, which represented a summary of the body 

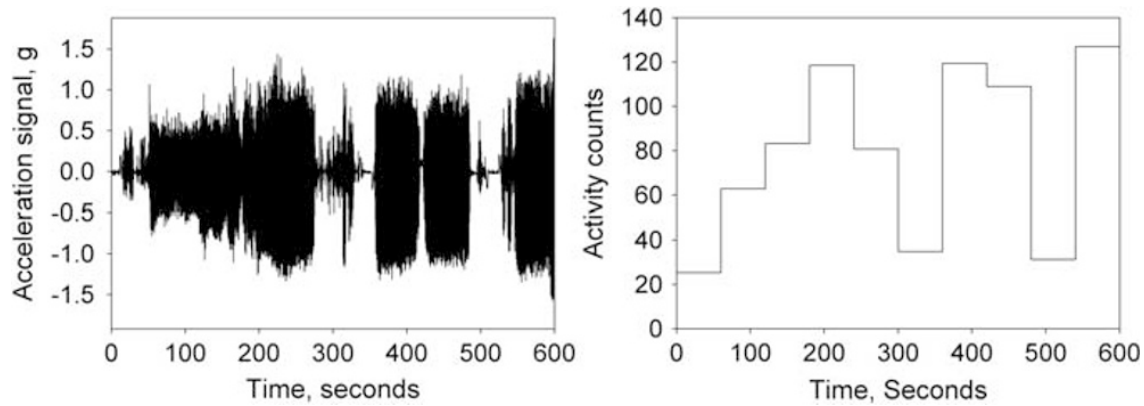

Figure 1 Acceleration signal recorded with a piezoelectric accelerometer (right) and the resulting activity counts per minute (left).

acceleration pattern measured in a time interval of usually $1 \mathrm{~min}$ (Figure 1). ${ }^{25}$

The daily profile and the amplitude of the measured activity counts are used to quantify the duration, frequency and intensity of physical activity. The disadvantage of using activity counts as output from the accelerometer is that the calculation process diminishes the detail of the collected information, and this reduces the ability to determine the physical activity pattern and the types of activity performed. Additionally, accelerometers equipped with piezoelectric sensors do not allow the detection of orientation of body parts or of static activities, as they can only detect variation in the acceleration of the body caused by movement. ${ }^{41}$

\section{Piezoresistive and capacitive accelerometers}

Advances in sensor technology over the past 15 years have resulted in the advent of piezoresistive and capacitive inertial sensors and the development of miniaturized accelerometers. $^{42}$ This second generation of activity monitors enabled physical activity measures to be developed because of their ability to detect posture and allocation. The first generation of piezoelectric accelerometers only recorded changes in the acceleration of the body caused by movement in order to quantify physical activity. ${ }^{41}$ Piezoresistive and capacitive accelerometers that are sensitive to both static and variable acceleration forces acting on the body have been used not solely for quantifying dynamic activities (for example, walking, running, cycling, exercising) but also for characterizing the sedentary portion of the day by distinguishing between sitting, standing and lying down. Indeed, the detection of gravity acceleration, which is a static force pulling constantly on the body, allowed the assessment of the inclination of the body from the vertical and consequently the identification of postures.

Unlike piezoelectric sensors, piezoresistive and capacitive sensors are 'passive components', which means that they require an external power source to measure body acceleration. For this reason, a critical aspect of portable accelerometers based on piezoresistive or capacitive technology is the operational lifetime, as the battery life is reduced by the sensor's energy demand. As compared with the first generation of accelerometers, some of the more advanced piezoresistive or capacitive accelerometers have increased data processing and storage capacity and provide rich information about physical activity, such as the daily engagement in different activity types. These accelerometers can directly execute complex calculations using software applications for physical activity recognition (Figure 2). Furthermore, the activity pattern can be analyzed with more detailed temporal information, which can reach fractions of a second, unlike piezoelectric accelerometers, which usually measure physical activity on a minuteby-minute basis.

The most widely studied of these activity monitors are the Tracmor $_{D}$ (Philips New Wellness Solutions, Lifestyle Incubator, Amsterdam, The Netherlands), the MiniMod (McRoberts, The Hague, The Netherlands), the latest version of the Actigraph (Model GT3X; Actigraph). Besides these commercially available accelerometers, other activity monitors made up by multiple units have been presented in the literature: the Intelligent Device for Energy Expenditure and physical Activity (IDEEA), ${ }^{43}$ the Physical Activity Monitoring System (PAMS) from James Levine's research group, ${ }^{14,44}$ the Wockets activity monitor from Stephen Intille's research group, $^{45}$ and the activity monitor from Henk Stam's and Hans Bussmann's research group. ${ }^{46,47}$ Piezocapacitive and piezoresistive accelerometers are usually more obtrusive than piezoelectric ones, have a shorter battery life and are often not integrated in a single device, but their accuracy is much higher as they can monitor multiple aspects of physical activity.

\section{Physical activity recognition}

An objective and automatic method for assessing physical activity types in free-living conditions remained unavailable for many years because of the lack of accelerometers capable of measuring sufficiently detailed information regarding body acceleration. Recent advances in activity-monitoring 

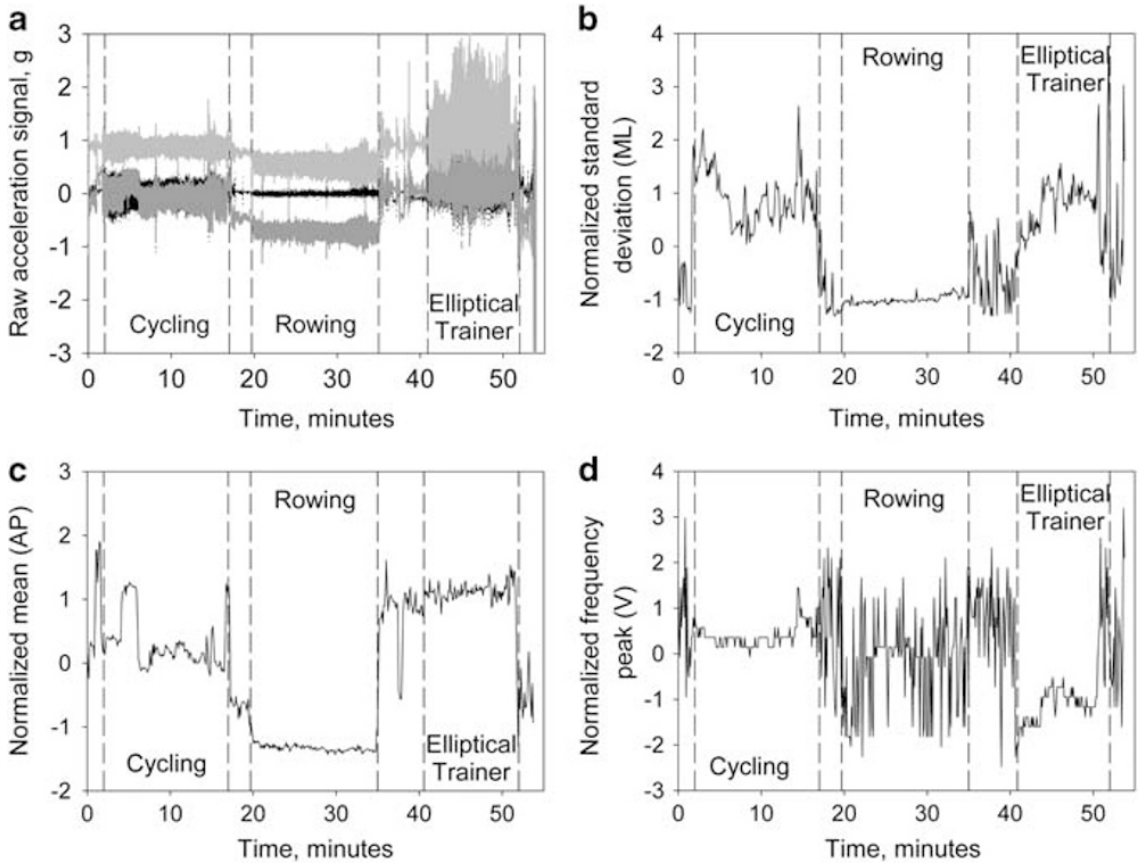

Figure 2 Information on body acceleration extracted using a capacitive accelerometer and an advanced data analysis method. It is possible to note the specific value and variability of features of the acceleration during cycling, rowing and elliptical trainer exercise. (a) Acceleration recorded by a capacitive accelerometer in three axis of measure (vertical, antero-posterior, medio-lateral) during cycling, rowing and exercising on an elliptical trainer. (b) Normalized standard deviation of the acceleration signal measured in the medio-lateral direction of the body (ML). (c) Normalized mean of the acceleration signal measured in the antero-posterior direction of the body (AP). (d) Normalized frequency peak of the acceleration signal power spectrum measured in the vertical direction of the body (V). The normalization has been based on the standard deviation of the distribution of data.

technology, and the introduction of piezoresistive and capacitive accelerometers have been followed by the development of physical activity recognition methods entailing the automated detection of physical activity types by a pattern classification system. ${ }^{48}$ A simple example of an activity recognition method based on a pattern classification system is represented by an accelerometer used for detecting steps. When the body acceleration exceeds a certain threshold, the system identifies that a step has been taken. The threshold value can be determined using automatic techniques to analyse the typical characteristics of the acceleration pattern during walking. This is the working principle of many inertial pedometers, and their complexity can grow to advanced classification systems capable of recognizing several activity types using accelerometers.

\section{Activity recognition using multiple or single-site accelerometers}

So far, almost all studies of physical activity recognition differed by the type and number of activities identified and by the location, type and number of accelerometers used (Table 1). Studies based on several accelerometers showed very high classification accuracy for the detection of postures and different types of ambulatory and cycling activities. ${ }^{45}$ Zhang et al. ${ }^{43}$ showed that the IDEEA, an activity monitor made up of five accelerometers, had a classification accuracy of more than $98 \%$ for recognizing 32 types of activity and posture using an artificial neural network algorithm. Bussman et al. ${ }^{49-52}$ reported that the activity monitor developed by their research laboratory, consisting of four accelerometers placed in different body locations, had an agreement rate of $89-90 \%$ with video observation in detecting a series of nine dynamic movements and different types of posture. Despite the obvious advantage for physical activity recognition provided by the use of multiple accelerometers to measure the movement of different body parts, there are practical limitations on the number and location of accelerometers that a subject can tolerate. For this reason, activity recognition schemes have been developed based on a single accelerometer, but the classification accuracy achieved was often poorer and the number of activity categories identified was smaller than that reported in studies using distributed systems (Table 1). Table 1 clearly shows a trade-off between the number of activity types and the number of accelerometers required for identification. Generic activity categories are classified with a relatively small number of accelerometers. Pober et al. ${ }^{53}$ reported an accuracy of $81 \%$ for identifying walking and certain lifestyle activities, like vacuum cleaning and working on a computer, 
Table 1 Studies on physical activity recognition using accelerometers, with information on the number of sensors, placement and performance with respect to the activities recognized, accuracy and signal processing

\begin{tabular}{|c|c|c|c|c|c|c|c|c|c|}
\hline Reference & Sensors & Placement & $\mathrm{n}$ & Types & Accuracy (\%) & Subjects & Algorithm & Features & Validation \\
\hline Van Laerhoven et al. ${ }^{57}$ & 30 & Along clothing & 10 & Sedentary, ambulatory, running, cycling & 94 & NA & ANN & $\mathrm{T}$ & NA \\
\hline Zhang et al. ${ }^{43}$ & 5 & Chest, thighs (2), feet (2) & 32 & Postures, gaits, limbs, movement, transitions & $>98$ & 76 & NA & NA & NA \\
\hline Bao et al. ${ }^{45}$ & 5 & Arm, wrist, hip, thigh, ankle & 20 & Ambulatory, households, cycling, sedentary & 84 & 20 & Decision tree & $\mathrm{T} / \mathrm{F}$ & Video \\
\hline Bussmann et al. $^{50}$ & 4 & Trunk, arm, thighs (2) & 10 & Postures, gaits, running, cycling, transition & 88 & 3 & Threshold & $\mathrm{T} / \mathrm{F}$ & Video \\
\hline Bussmann et al. $^{49}$ & 4 & Sternum, arm, thighs (2) & 10 & Postures, gaits, running, cycling, transition & 90 & 8 & Threshold & $\mathrm{T} / \mathrm{F}$ & Video \\
\hline Foerster et al..$^{56}$ & 4 & Sternum, wrist, thigh, ankle & 9 & Lying, sitting, standing, ambulatory, cycling & 67 & 24 & k-Nearest neighbor & NA & Observ. \\
\hline Veltink et al. ${ }^{47}$ & 3 & Sternum, thighs (2) & 7 & Lying, sitting, standing, ambulatory, cycling & NA & 10 & Threshold & $\mathrm{T}$ & NA \\
\hline Uiterwaal et al. ${ }^{80}$ & 3 & Thigh, waist (2) & 5 & Lying, sitting, standing, ambulatory, playing & 86 & 1 & Threshold & NA & Video \\
\hline Zhang et al. ${ }^{81}$ & 1 & Sole foot & 4 & Locomotion & $>98$ & 40 & ANN & $\mathrm{T}$ & Test \\
\hline Pober et al. ${ }^{53}$ & 1 & Waist & 4 & Locomotion, household, sitting & 81 & 6 & HMM & $\mathrm{T}$ & NA \\
\hline Staudenmayer et al. ${ }^{82}$ & 1 & Waist & 4 & Sedentary, walking, sport, household & 89 & 48 & ANN & $\mathrm{T}$ & NA \\
\hline Karantonis et al. ${ }^{83}$ & 1 & Waist & 3 & Lying, sitting, walking & $74-90$ & 6 & Threshold & $\mathrm{T}$ & NA \\
\hline Yang et al. ${ }^{84}$ & 1 & Upper arm & 9 & Rest, ambulation, eating, playing, reading & 75 & NA & Fuzzy-Bayesian net & $\mathrm{T}$ & NA \\
\hline Manohar et al. ${ }^{85}$ & 1 & Ear & 3 & Lying, sedentary, walking & $>99$ & 18 & NA & NA & NA \\
\hline Dijkstra et al..$^{86}$ & 1 & Waist & 5 & Lying, sitting, standing, walking, shuffling & 80 & 20 & NA & NA & Video \\
\hline
\end{tabular}

Abbereviations: ANN, artificial neural net; F, frequency domain; HMM, hidden Markov model; $n$, number of activity types; NA, not available; Observ, behavioral observation; T, time domain; Test, supervised test; Types, activity types; Video, video recordings.

by using an Actigraph accelerometer (Actigraph). We showed that identifying three different postures, that is, lying, sitting and standing, and three types of locomotion movements, that is, walking, running and cycling, was accurately achieved using a single accelerometer positioned at the waist. ${ }^{54}$ However, standing was often confused with sitting and for this reason in later studies ${ }^{55}$ the sitting and standing classes were combined together in a single category describing static events.

Multiple accelerometers allow the successful distinction between sitting and standing. ${ }^{43,44,46,49-51,56,57}$ Intuitively, a single piezoresistive or capacitive accelerometer located on the upper side of the thigh permits high accuracy for classifying postures. However, this wearing position is adversely affected by incorrect placement and may be perceived as uncomfortable by users. A potential solution for identifying sitting and standing using one accelerometer is the development of algorithms for classification of postural transitions. ${ }^{58}$ Nevertheless, the level of accuracy achieved for posture classification using multiple motion sensors is difficult to attain with a single accelerometer placed around the waist.

\section{Validating activity recognition methods}

The validation of an activity type classification method requires testing the reproducibility of the recognition performance in free-living conditions and in subject populations different from the one used for training. Indeed, measuring physical activity in daily life may introduce unexpected variability in the acceleration signal, which leads to poor reproducibility of laboratory classification accuracy. Furthermore, classification errors arise because of between-subject variability in accelerometer output for the same activity. Ideally, a successful classification system should overcome these factors and, with data from a range of previous subjects, allow the accurate identification of activity types from an unseen individual in daily life. Testing the classification accuracy has often been based on crossvalidation strategies using a training dataset. Only a few studies validated the recognition performance with data from unseen individuals and in free-living conditions, for example, by using video observations as a reference measure of activity types (Table 1 ).

We showed the classification performance of a decision tree recognition model, as tested on a population of subjects not used for training purposes, to have an average accuracy of $92 \%$, with activity specific accuracies from $81-100 \% .{ }^{55,59}$ Validation in free-living conditions was also performed by comparing the classification outcome of the decision tree with a 'reference truth' represented by the output of the IDEEA activity monitor in combination with a diary for self-reporting of cycling events, in a population of 16 subjects. The participants in this trial were instructed to wear the Tracmor (Philips Research) and the IDEEA activity monitor simultaneously over intervals of $13 \mathrm{~h}$, from 9 a.m. until 10 p.m., in free-living conditions. The IDEEA was chosen as a reference based on the capacity to identify 32 different activity types with a nearly 100\% classification accuracy. ${ }^{43}$ There was no significant difference between the Tracmor (Philips Research) assessed duration of the activity types and the reference truth (Figure 3), suggesting that the presented method was valid for identifying activities in freeliving conditions and the classification rules applied for unseen individuals.

\section{Activity energy expenditure estimation using accelerometers}

Assessment of activity energy expenditure (AEE) allows to define a dose-effect relationship between physical activity 

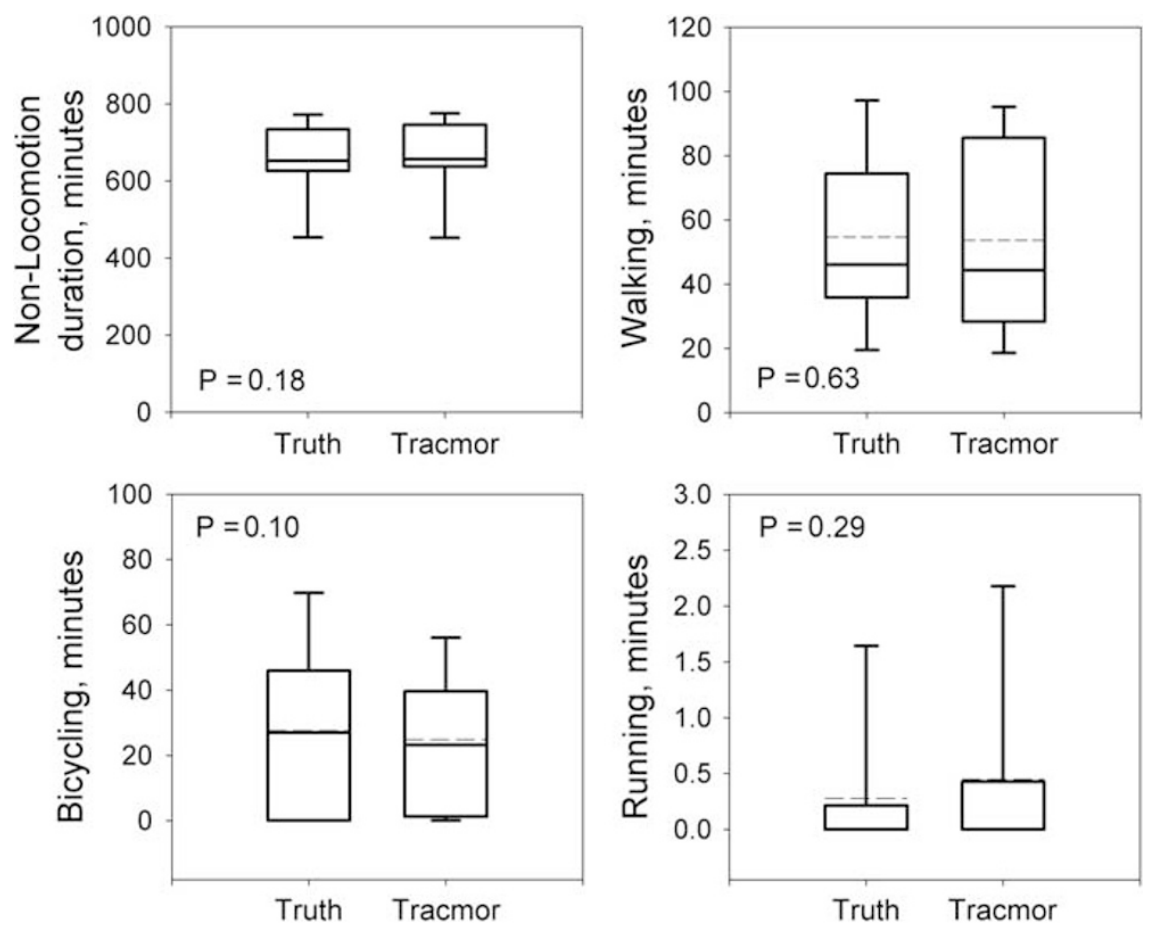

Figure 3 Validation of the decision-tree recognition method in daily life.

and a physiological response. On a subjective level, the acceleration of the body is theoretically proportional to the muscular forces responsible for movement and, thus, to energy expenditure. Based on this principle, accelerometers have been tested against indirect calorimetry to determine whether measurements of physical activity duration and intensity, namely activity counts scored over time together with subjects' characteristics, can reliably estimate energy expenditure. Several studies have focused on the use of multiple-linear regression techniques to predict AEE from activity counts and parameters descriptive of body size, like weight, height, body mass index or body composition. Many accelerometers have been tested under laboratory conditions during standardized activities using a portable or wholeroom indirect calorimeter to measure energy expenditure. The AEE estimation accuracy varied according to the device and the test conditions. The correlation coefficient between activity counts measured with the Actigraph and the metabolic cost of walking was between $59-86 \% .{ }^{60}$ Bouten et $a l .{ }^{61}$ reported that Tracmor (Philips Research) activity counts can predict energy expenditure during walking with an accuracy of $95 \%$. However, during sedentary activities the accuracy dropped to $67 \%$. Laboratory tests have shown that prediction equations developed during ambulatory activities were not adequate to describe the relationship between activity counts and the metabolic cost of sedentary and lifestyle-related activities. ${ }^{62,63}$ Considering that accelerometers should be able to describe the energy cost of any type of activity performed in daily life, validations in free-living conditions have also been done by comparing measurements of activity counts to doubly-labeled water. Recent reviews ${ }^{26,35}$ reported that not all accelerometers can accurately estimate AEE in free-living conditions, and subjects' characteristics are often the only significant contributors to the explained variance in AEE of the prediction models. The Tracmor accelerometer (Philips Research) was found to provide an accurate estimate of energy expenditure in both laboratory and free-living conditions, as the measured activity counts significantly contributed to the explained variance in AEE. ${ }^{64,65}$ A more recent version of this accelerometer, the DirectLife tri-axial accelerometer for movement registration $\left(\right.$ Tracmor $_{\mathrm{D}}$; Philips New Wellness Solutions, Lifestyle Incubator), showed similar prediction accuracy of energy expenditure in free-living conditions. ${ }^{66}$ The activity counts measured with Tracmor $_{\mathrm{D}}$ (Philips New Wellness Solutions, Lifestyle Incubator) added $23 \%$ to the explained variation in AEE after adjustment for subject characteristics, and the prediction model had a standard error of estimation of $0.9 \mathrm{MJ} \mathrm{day}^{-1}$.

Although significant estimations of AEE have been shown with an accelerometer, there are pragmatic limitations to the use of activity counts to estimate energy expenditure. Some of these are: the fact that the relationship between energy expenditure and activity counts varies according to the activity type, ${ }^{60}$ and the fact that activity counts do not reflect external work performed during physical activity, such as walking on slopes or carrying loads. ${ }^{25,61}$ Additionally, missing data and lack of information about fatigue and physical fitness level may reduce the estimation accuracy of energy expenditure using accelerometers. ${ }^{41,67}$ 


\section{Improvements in energy expenditure estimation}

Several approaches have recently been considered with a view to eliminating limitations of accelerometry-based estimations of energy expenditure. Firstly, more complex modeling techniques have been used to estimate energy expenditure from accelerometer data. Crouter et al. ${ }^{63}$ proposed to predict energy expenditure using a two-regression equation model based on activity counts measured in epochs of $10 \mathrm{~s}$. Rothney et al. ${ }^{68}$ developed an artificial neural network to process the raw acceleration signal measured during a 24-h stay in a respiration chamber to improve energy expenditure estimations.

Combining accelerometers with physiological measurements, such as heart rate r9-73 $^{6 r}$ body temperature and galvanic skin response ${ }^{74}$ has also been attempted for reducing AEE estimation error. However, validation of these methods in free-living conditions, using doubly-labeled water as a reference measure, is limited. Assah et al. ${ }^{75}$ showed that measuring heart rate and acceleration allows accurate estimation of AEE in free-living conditions. The mean absolute error of the AEE prediction model was $29 \mathrm{~kJ} \mathrm{~kg}^{-1} \mathrm{day}^{-1}$ or $2.0 \mathrm{MJ} \mathrm{day}^{-1}$ for a $70-\mathrm{kg}$ subject. Zhakeri et al. ${ }^{73}$ presented a method for predicting 24-h energy expenditure in a respiration chamber using data on body acceleration, heart rate and subject characteristics, and the root mean squared error was $0.7 \mathrm{MJ} \mathrm{day}^{-1}$. Johannsen et al. ${ }^{74}$ showed that the Armband multi-sensor system (BodyMedia, Pittsburgh, PA, USA) could be used to accurately estimate energy expenditure in free-living conditions. The information on skin temperature, galvanic-skin response and acceleration collected by the Armband (BodyMedia), together with subject characteristics, permitted predictions of total energy expenditure (TEE) with a mean absolute error of $0.9 \mathrm{MJ} \mathrm{day}^{-1}$. However, the algorithm used by the Armband (BodyMedia) to predict TEE is unpublished and this hampers the understanding of whether physiological measurements and body acceleration additively and significantly contribute to the TEE estimation.

\section{Physical activity recognition and energy expenditure estimation}

Physical activity recognition significantly improves the estimation of energy expenditure by disentangling the issue of the non-uniqueness of the relationship between activity counts and energy expenditure for different activity types, which is imputed to reduce energy expenditure estimation accuracy. ${ }^{59}$ The method proposed in a previous study ${ }^{59}$ reduced the AEE root mean squared error by $0.15 \mathrm{MJ} \mathrm{day}^{-1}$, and objective assessment of activity type intensity could even further improve the AEE prediction accuracy achieved by physical activity recognition.
Physical activity recognition has the potential to transform measurement methodologies of physical activity based on accelerometers. Indeed, the outcome of an activity recognition method is directly comparable to any other, upon selection of similar activity categories. This represents a novelty in the field, as accelerometer output is variable among different monitors because of dissimilar sensor type and specifications, that is, dynamic range, sensitivity, sampling frequency, wearing position, filtering and integration epoch for the calculation of activity counts. Standardizing accelerometer output helps developing generic prediction models of energy expenditure. For example, the prediction models of TEE and AEE presented in the study of Bonomi et al. ${ }^{59}$ are applicable to the output of any measurement instrument capable of objectively determining the daily duration of lying, sitting/standing, actively standing, walking, running and cycling.

\section{Physical activity and health promotion}

Public health guidelines on physical activity recommend the engagement in $30 \mathrm{~min}$ of moderate-intensity physical activity on 5 days of the week to promote and maintain health. ${ }^{76}$ In addition, high-intensity activity is suggested in combination with moderate-intensity activity to improve health even further. ${ }^{3}$ Other guidelines suggest reaching a certain amount of steps per day to reduce the risk of diseases. ${ }^{77}$ However, these rules were developed from assumptions about the effects of regular physical activity rather than about the relationship between a dose of physical activity and physiological responses. The reason for this is the lack of objective and detailed measures on intensity, duration and type of physical activity, and on the related physiological responses. ${ }^{24,35}$ Complementary recommendations target aspects of sedentary time for health promotion. ${ }^{78,79}$ Interventions aimed at decreasing sedentary time and changing a particular pattern of overly sedentary behavior are mainly useful in patient populations prone to physical inactivity, to achieve health benefits and prevent the onset of chronic diseases. ${ }^{78,79}$ Thus, advanced piezoresistive or capacitive accelerometers able to determine the characteristics of individuals' sedentary behavior and of low-intensity activities can be of extreme importance for supporting lifestyle interventions in overweight and obese subjects, as their behavior is predominantly sedentary. ${ }^{14,16}$

Considering the between-individual variability in physiological response to physical activity due to the differences in size of the body carried during movement, it is reasonable to assume that overweight and obese individuals would experience a higher metabolic response than lean ones during the same activity. Thus, in order to increase the effectiveness of lifestyle interventions for health promotion, different doses of physical activity could be recommended to different individuals. In this context activity monitors can 
play a key role, not only to improve participants' motivation during an activity intervention program, but also to make possible the personalization and contextualization of activity guidelines for lifestyle changes.

The key aspect of an activity monitor used to support an activity program for health promotion is that it should offer a reliable assessment of physical activity and energy expenditure so that the user will consistently trust the feedback received from the monitoring tool on his/her own activity level and achievements. Secondly, the user should be able to easily interpret the accurate information received from the activity monitor and respond adequately with a view to reaching a specific target defined in the activity program. In view of these two facets, activity-monitoring technology is moving in the right direction to offer appropriate support for health promotion.

Pedometers are widely accessible, given the relatively low cost, but their accuracy is very poor both for measuring physical activity and predicting energy expenditure in overweight and obese subjects. ${ }^{26,34,35}$ On the other hand, users can easily interpret pedometer output and understand the action needed to reach a predefined target.

The first generation of accelerometers is certainly more accurate at assessing physical activity and energy expenditure than pedometers, as they detect the quantitative aspects of both ambulatory and non-ambulatory activities. However, they are more expensive and can underestimate the metabolic cost of some activities, as the relationship between body movement and energy expenditure is contingent upon activity type. ${ }^{59,67}$ The second generation of accelerometers is extremely accurate at measuring physical activity by determining individuals' activity behavior and estimating energy expenditure according to the types of activities engaged in. However, they are often obtrusive and only a very few have been developed to a level suitable for use in a population of subjects following a lifestyle intervention. The interpretability of accelerometer output is the weakness of these activity monitors. Indeed, users may not understand sufficiently information, such as activity counts and calories burned. A solution to this problem has been proposed and implemented in the Tracmor $_{D}$ activity monitor (Philips New Wellness Solutions, Lifestyle Incubator). Tracmor ${ }_{D}$ (Philips New Wellness Solutions, Lifestyle Incubator) provides visual feedback to the activity monitor user in terms of percentage of activity performed as compared with a specific target established in the intervention program. ${ }^{66}$ This would increase the ability of the user to act in response to the indication of an inadequate activity level.

\section{Conclusion}

Activity monitors are portable systems able to quantify physical activity by measuring body movement. These tools are effective as motivational devices for individuals following a lifestyle intervention. Pedometers are inexpensive and the information provided to the user is straightforwardly interpretable, but their poor accuracy in overweight and obese subjects may generate counterproductive effects and results in frustration and low compliance with an intervention program. Accelerometers are highly accurate tools for characterizing sedentary time and assessing physical activity and energy expenditure, which is useful for generating personalized activity guidelines for health promotion. However, advanced accelerometers are often obtrusive, expensive and their output is often inadequate for stimulating the actions of uneducated users. One exception is the Tracmor $_{D}$ (Philips New Wellness Solutions, Lifestyle Incubator), which offers easily interpretable feedback for improving individuals' awareness of their activity level as compared with personalized targets designed to achieve health benefits.

\section{Conflict of interest}

The authors declare no conflict of interest.

\section{Acknowledgements}

This study was funded by Philips Research.

\section{References}

1 Flegal KM, Carroll MD, Ogden CL, Curtin LR. Prevalence and trends in obesity among US adults, 1999-2008. JAMA 2010; 303: 235-241.

2 Malnick SDH, Knobler H. The medical complications of obesity. QJM 2006; 99: 565-579.

3 Haskell WL, Lee IM, Pate RR, Powell KE, Blair SN, Franklin BA et al. Physical activity and public health: updated recommendation for adults from the American College of Sports Medicine and the American Heart Association. Med Sci Sports Exerc 2007; 39: 1423-1434.

4 Caspersen CJ, Christenson GM, Pollard RA. Status of the 1990 physical fitness and exercise objectives-evidence from NHIS 1985. Public Health Rep 1986; 101: 587-592.

5 Grant M. A short history of classical civilization. In: Herodotus, The Persian War, vol. VIII. Weidenfeld and Nicolson: London, UK, 1991, p 26.

6 Kriska AM, Saremi A, Hanson RL, Bennett PH, Kobes S, Williams DE et al. Physical activity, obesity, and the incidence of type 2 diabetes in a high-risk population. Am J Epidemiol 2003; 158: 669-675.

7 Blair SN, Brodney S. Effects of physical inactivity and obesity on morbidity and mortality: current evidence and research issues. Med Sci Sports Exerc 1999; 31: S646-S662.

8 Fang J, Wylie-Rosett J, Cohen HW, Kaplan RC, Alderman MH. Exercise, body mass index, caloric intake, and cardiovascular mortality. Am J Prev Med 2003; 25: 283-289.

9 Neville CE, Murray LJ, Boreham CA, Gallagher AM, Twisk J, Robson PJ et al. Relationship between physical activity and bone mineral status in young adults: the Northern Ireland Young Hearts Project. Bone 2002; 30: 792-798.

10 Gotay CC. Behavior and cancer prevention. J Clin Oncol 2005; 23: 301-310. 
11 Westerterp KR. Physical activity, food intake, and body weight regulation: insights from doubly labeled water studies. Nutr Rev 2010; 68: 148-154.

12 Tudor-Locke C, Brashear M, Johnson W, Katzmarzyk P. Accelerometer profiles of physical activity and inactivity in normal weight, overweight, and obese US men and women. Int J Behav Nutr Phys Act 2010; 7: 60.

13 Ekelund U, Aman J, Yngve A, Renman C, Westerterp K, Sjostrom M. Physical activity but not energy expenditure is reduced in obese adolescents: a case-control study. Am J Clin Nutr 2002; 76: 935-941.

14 Levine JA, Lanningham-Foster LM, McCrady SK, Krizan AC, Olson LR, Kane $\mathrm{PH}$ et al. Interindividual variation in posture allocation: possible role in human obesity. Science 2005; 307: $584-586$.

15 Chong PK, Jung RT, Rennie MJ, Scrimgeour CM. Energy expenditure in lean and obese diabetic patients using the doubly labelled water method. Diabet Med 1993; 10: 729-735.

16 Johannsen DL, Welk GJ, Sharp RL, Flakoll PJ. Differences in daily energy expenditure in lean and obese women: The role of posture allocation. Obesity 2008; 16: 34-39.

17 Meijer GA, Westerterp KR, van Hulsel AM, ten Hoor F. Physical activity and energy expenditure in lean and obese adult human subjects. Eur J Appl Physiol Occup Physiol 1992; 65: 525-528.

18 Levine JA, Schleusner SJ, Jensen MD. Energy expenditure of nonexercise activity. Am J Clin Nutr 2000; 72: 1451-1454.

19 Schoeller DA, Jefford G. Determinants of the energy costs of light activities: inferences for interpreting doubly labeled water data. Int J Obes Relat Metab Disord 2002; 26: 97-101.

20 Lamonte MJ, Ainsworth BE. Quantifying energy expenditure and physical activity in the context of dose response. Med Sci Sports Exerc 2001; 33: S370-S378.

21 Mark AE, Janssen I. Dose-response relation between physical activity and blood pressure in youth. Med Sci Sports Exerc 2008; 40: 1007-1012.

22 Vainionpaa A, Korpelainen R, Kaikkonen H, Knip M, Leppaluoto J, Jamsa T. Effect of impact exercise on physical performance and cardiovascular risk factors. Med Sci Sports Exerc 2007; 39: 756-763.

23 Macfarlane DJ, Lee CCY, Ho EYK, Chan KL, Chan D. Convergent validity of six methods to assess physical activity in daily life. J Appl Physiol 2006; 101: 1328-1334.

24 Montoye HJ, Kempen HCG, Saris WHM, Washburn RA. Measuring Physical Activity and Energy Expenditure. Human Kinetics: IL, 1996.

25 Bouten CVC, Koekkoek KTM, Verduin M, Kodde R, Janssen JD. A triaxial accelerometer and portable data processing unit for the assessment of daily physical activity. IEEE Trans Biomed Eng 1997; 44: 136-147.

26 Plasqui G, Westerterp KR. Physical activity assessment with accelerometers: an evaluation against doubly labeled water. Obesity 2007; 15: 2371-2379.

27 Matthews CE, Ainsworth BE, Thompson RW, Bassett DR. Sources of variance in daily physical activity levels as measured by an accelerometer. Med Sci Sports Exerc 2002; 34: 1376-1381.

28 Bravata DM, Smith-Spangler C, Sundaram V, Gienger AL, Lin N, Lewis $\mathrm{R}$ et al. Using pedometers to increase physical activity and improve health. JAMA 2007; 298: 2296-2304.

29 Clemes SA, Griffiths PL, Hamilton SL. Four-week pedometerdetermined activity patterns in normal weight and overweight UK adults. Int J Obes 2007; 31: 261-266.

30 Bassett Jr DR, Cureton AL, Ainsworth BE. Measurement of daily walking distance-questionnaire versus pedometer. Med Sci Sports Exerc 2000; 32: 1018-1023.

31 Crouter SE, Schneider PL, Bassett DRJ. Spring-levered versus piezo-electric pedometer accuracy in overweight and obese adults. Med Sci Sports Exerc 2005; 37: 1673-1679.

32 Melanson EL, Knoll JR, Bell ML, Donahoo WT, Hill JO, Nysse LJ et al. Commercially available pedometers: considerations for accurate step counting. Prev Med 2004; 39: 361-368.
33 Clemes SA, O'Connell S, Rogan LM, Griffiths PL. Evaluation of a commercially available pedometer used to promote physical activity as part of a national programme. Br J Sports Med 2010; 44: 1178-1183.

34 Tudor-Locke C, Williams JE, Reis JP, Pluto D. Utility of pedometers for assessing physical activity: convergent validity. Sports Med 2002; 32: 795-808.

35 Leenders N, Sherman WM, Nagaraja HN, Kien CL. Evaluation of methods to assess physical activity in free-living conditions. Med Sci Sports Exerc 2001; 33: 1233-1240.

36 Melanson Jr EL, Freedson PS. Validity of the Computer Science and Applications, Inc. (CSA) activity monitor. Med Sci Sports Exerc 1995; 27: 934-940.

37 Garcia E, Hang Ding Sarela A, Karunanithi M. Can a mobile phone be used as a pedometer in an outpatient cardiac rehabilitation program? IEEE/ICME International Conference on Complex Medical Engineering (CME), Gold Coast, QSL, Australia, 2010, pp 250-253.

38 Kevin P, William GG, Fred R, Stephen SI. Health and the mobile phone. Am J Prev Med 2008; 35: 177-181.

39 Antonsson EK, Mann RW. The frequency content of gait. J Biomech 1985; 18: 39-47.

40 Linden D, Reddy TB. Principle of operation - Basic concepts. In: Linden D, Reddy TB (eds). Handbook of Batteries, 3rd edn. McGraw-Hill: New York, 2002, pp 3-17.

41 Chen KY, Bassett Jr DR. The technology of accelerometry-based activity monitors: current and future. Med Sci Sports Exerc 2005; 37: S490-S500.

42 Bao M. Micro Mechanical Transducers: Pressure Sensors, Accelerometers, and Gyroscopes vol. 8. Elsevier: Amsterdam, 2000.

43 Zhang K, Werner P, Sun M, Pi-Sunyer FX, Boozer CN. Measurement of human daily physical activity. Obes Res 2003; 11: 33-40.

44 Levine JA, McCrady SK, Lanningham-Foster LM, Kane PH, Foster RC, Manohar CU. The role of free-living daily walking in human weight gain and obesity. Diabetes 2008; 57: 548-554.

45 Bao L, Intille SS. Activity recognition from user-annotated acceleration data. Pervas Comput Proc 2004; 3001: 1-17.

46 Bussmann JB, Martens WL, Tulen JH, Schasfoort FC, van den Berg-Emons HJ, Stam HJ. Measuring daily behavior using ambulatory accelerometry: the activity monitor. Behav Res Methods Instrum Comput 2001; 33: 349-356.

47 Veltink PH, Bussmann HB, de Vries W, Martens WL, Van Lummel RC. Detection of static and dynamic activities using uniaxial accelerometers. IEEE Trans Rehabil Eng 1996; 4: 375-385.

48 Duda RO, Hart PE, Stork DG. Pattern Classification 2nd edn. Wiley-Interscience: New York, 2000. 654pp.

49 Bussmann HB, Reuvekamp PJ, Veltink PH, Martens WL, Stam HJ. Validity and reliability of measurements obtained with an 'activity monitor' in people with and without a transtibial amputation. Phys Ther 1998; 78: 989-998.

50 Bussmann JB, Tulen JH, van Herel EC, Stam HJ. Quantification of physical activities by means of ambulatory accelerometry: a validation study. Psychophysiology 1998; 35: 488-496.

51 Bussmann JB, van de Laar YM, Neeleman MP, Stam HJ. Ambulatory accelerometry to quantify motor behaviour in patients after failed back surgery: a validation study. Pain 1998; 74: 153-161.

52 van den Berg-Emons HJ, Bussmann JB, Balk AH, Stam HJ. Validity of ambulatory accelerometry to quantify physical activity in heart failure. Scand J Rehabil Med 2000; 32: 187-192.

53 Pober DM, Staudenmayer J, Raphael C, Freedson PS. Development of novel techniques to classify physical activity mode using accelerometers. Med Sci Sports Exerc 2006; 38: 1626-1634.

54 Bonomi AG, Goris AH, Yin B, Westerterp KR. Detection of type, duration, and intensity of physical activity using an accelerometer. Med Sci Sports Exerc 2009; 41: 1770-1777.

55 Bonomi AG, Plasqui G, Goris AHC, Westerterp KR. Aspects of activity behavior as a determinant of the 
physical activity level. Scand J Med Sci Sports 2011; doi:10.1111/ j.1600.0838.2010.01130.x.

56 Foerster F, Smeja M, Fahrenberg J. Detection of posture and motion by accelerometry: a validation study in ambulatory monitoring. Comput Human Behav 1999; 15: 571-583.

57 Van Laerhoven K. Spine versus porcupine: a study in distributed wearable activity recognition. Eighth IEEE Int Symp Wearable Comput (ISWC 2004) 2004; 142-149.

58 Najafi B, Aminian K, Paraschiv-Ionescu A, Loew F, Bula CJ, Robert P. Ambulatory system for human motion analysis using a kinematic sensor: monitoring of daily physical activity in the elderly. IEEE Trans Biomed Eng 2003; 50: 711-723.

59 Bonomi AG, Plasqui G, Goris AH, Westerterp KR. Improving assessment of daily energy expenditure by identifying types of physical activity with a single accelerometer. J Appl Physiol 2009; 107: 655-661.

60 Crouter SE, Churilla JR, Bassett Jr DR. Estimating energy expenditure using accelerometers. Eur J Appl Physiol 2006; 98: 601-612.

61 Bouten CV, Westerterp KR, Verduin M, Janssen JD. Assessment of energy expenditure for physical activity using a triaxial accelerometer. Med Sci Sports Exerc 1994; 26: 1516-1523.

62 Bassett Jr DR, Ainsworth BE, Swartz AM, Strath SJ, O'Brien WL, King GA. Validity of four motion sensors in measuring moderate intensity physical activity. Med Sci Sports Exerc 2000; 32: S471-S480.

63 Crouter SE, Clowers KG, Bassett DR. A novel method for using accelerometer data to predict energy expenditure. J Appl Physiol 2006; 100: 1324-1331.

64 Bouten CV, Verboeket-van de Venne WP, Westerterp KR, Verduin $\mathrm{M}$, Janssen JD. Daily physical activity assessment: comparison between movement registration and doubly labeled water. J Appl Physiol 1996; 81: 1019-1026.

65 Plasqui G, Joosen A, Kester AD, Goris AHC, Westerterp K. Measuring free-living energy expenditure and physical activity with triaxial accelerometry. Obes Res 2005; 13: 1363-1369.

66 Bonomi AG, Plasqui G, Goris AHC, Westerterp KR. Estimation of free-living energy expenditure using a novel activity monitor designed to minimize obtrusiveness. Obesity 2010; 18: 1845-1851.

67 van Hees VT, Ekelund U. Novel daily energy expenditure estimation by using objective activity type classification: where do we go from here? J Appl Physiol 2009; 107: 639-640.

68 Rothney MP, Neumann M, Beziat A, Chen KY. An artificial neural network model of energy expenditure using nonintegrated acceleration signals. J Appl Physiol 2007; 103: 1419-1427.

69 Brage S, Brage N, Ekelund U, Luan J, Franks PW, Froberg K et al. Effect of combined movement and heart rate monitor placement on physical activity estimates during treadmill locomotion and free-living. Eur J Appl Physiol 2006; 96: 517-524.

70 Brage S, Brage N, Franks PW, Ekelund U, Wong MY, Andersen LB et al. Branched equation modeling of simultaneous accelerometry and heart rate monitoring improves estimate of directly measured physical activity energy expenditure. J Appl Physiol 2004; 96: 343-351.

71 Hay DC, Wakayama A, Sakamura K, Fukashiro S. Improved estimation of energy expenditure by artificial neural network modeling. App Physiol Nutr Metab 2008; 33: 1213-1222.
72 Strath SJ, Brage S, Ekelund U. Integration of physiological and accelerometer data to improve physical activity assessment. Med Sci Sports Exerc 2005; 37: S563-S571.

73 Zakeri IF, Adolph AL, Puyau MR, Vohra FA, Butte NF. Multivariate adaptive regression splines models for the prediction of energy expenditure in children and adolescents. J Appl Physiol 2010; 108: 128-136.

74 Johannsen DL, Calabro MA, Stewart J, Franke W, Rood JC, Welk GJ. Accuracy of armband monitors for measuring daily energy expenditure in healthy adults. Med Sci Sports Exerc 2010; 42: 2134-2140.

75 Assah FK, Ekelund U, Brage S, Wright A, Mbanya JC, Wareham NJ. Accuracy and validity of a combined heart rate and motion sensor for the measurement of free-living physical activity energy expenditure in adults in Cameroon. Int J Epidemiol 2011; 40: $112-120$.

76 Pate RR, Pratt M, Blair SN, Haskell WL, Macera CA, Bouchard $\mathrm{C}$ et al. Physical activity and public health. a recommendation from the Centers for Disease Control and Prevention and the American College of Sports Medicine. JAMA 1995; 273: 402-407.

77 Tudor-Locke C, Bassett Jr DR. How many steps/day are enough?: preliminary pedometer indices for public health. Sports Med 2004; 34: $1-8$.

78 Healy GN, Dunstan DW, Salmon J, Cerin E, Shaw JE, Zimmet PZ et al. Breaks in sedentary time: beneficial associations with metabolic risk. Diabetes Care 2008; 31: 661-666.

79 Owen N, Bauman A, Brown W. Too much sitting: a novel and important predictor of chronic disease risk? Br J Sports Med 2009; 43: 81-83.

80 Uiterwaal M, Glerum EBC, Busser HJ, van Lummel RC. Ambulatory monitoring of physical activity in working situations, a validation study. J Med Eng Technol 1998; 22: 168-172.

81 Zhang K, Sun M, Lester DK, Pi-Sunyer FX, Boozer CN, Longman RW. Assessment of human locomotion by using an insole measurement system and artificial neural networks. $J$ Biomech 2005; 38: 2276-2287.

82 Staudenmayer J, Pober D, Crouter S, Bassett D, Freedson P. An artificial neural network to estimate physical activity energy expenditure and identify physical activity type from an accelerometer. J Appl Physiol 2009; 107: 1300-1307.

83 Karantonis DM, Narayanan MR, Mathie M, Lovell NH, Celler BG. Implementation of a real-time human movement classifier using a triaxial accelerometer for ambulatory monitoring. IEEE Trans Inf Technol Biomed 2006; 10: 156-167.

84 Yang S-I, Cho S-B. Recognizing human activities from accelerometer and physiological sensors. In: Sukhan L, Hanseok K, Hernsoo H (eds). Multisensor Fusion and Integration for Intelligent Systems. Springer, 2009, pp 187-199.

85 Manohar C, McCrady S, Pavlidis IT, Levine JA. An accelerometerbased earpiece to monitor and quantify physical activity. J Phys Act Health 2009; 6: 781-789.

86 Dijkstra B, Kamsma Y, Zijlstra W. Detection of gait and postures using a miniaturised triaxial accelerometer-based system: accuracy in community-dwelling older adults. Age Ageing 2010; 39: $259-262$ 